\title{
Study on Urban Green Space System Planning and Implementation Evaluation
}

\author{
Zhang Chunxiao, Wan Dan*, Jiang Qi, Feng Kexin \\ Sichuan Institute of Urban Planning and Design, China, 610000, Chengdu
}

Keywords: Green space system; Planning implementation evaluation; Evaluation indicators

\begin{abstract}
China's urban planning has gradually transited from the incremental planning stage to the planning of reduction planning and stock planning. Under the background of ecological civilization construction, urban green space is increasingly concerned by the government and the public. Urban green space system planning has become an important means to coordinate the allocation of green space resources and rationally construct the urban ecological environment. This paper draws on the theory and practice of planning implementation evaluation in the field of land use planning and urban planning. Based on the progress of the system planning implementation evaluation, the concept of urban green space system planning implementation evaluation is defined and the urban green space system planning implementation evaluation index system is constructed. Finally, the paper summarizes and forecasts the implementation evaluation of China's urban green space system planning.
\end{abstract}

\section{Introduction}

At present, China's theory and practice on planning implementation evaluation focuses on land use planning and urban master planning ${ }^{[1]}$. The implementation evaluation of land use planning is the focus of research in the field of land management in China. It refers to the objective evaluation and summary of the implementation process of the evaluation year and the spatio-temporal effect of the implementation results in accordance with certain standards and methods during the implementation of the $\operatorname{plan}^{[2]}$. In the early 20th century, megacities such as Beijing, Shanghai and Shenzhen took the lead in conducting evaluation studies on urban planning implementation. Urban planning implementation evaluation research focuses on the implementation of consistency evaluation and implementation performance evaluation ${ }^{[3-5]}$. Urban green space system planning and evaluation evaluates the status quo of green space system from various aspects such as planning indicators, ecological benefits and landscape ecological pattern, and proposes urban green space system planning optimization measures.

Monitoring after the implementation of the plan is called "assessment" or "evaluation". Evaluation has the meaning of evaluation and estimation. It is the behavior and process of analyzing and calculating the evaluation object and publishing professional opinions based on the evaluation purpose and principle according to the corresponding evaluation purpose and principle ${ }^{[6-8]}$. The urban green space system planning implementation evaluation refers to the implementation of the urban green space system planning to a certain stage. The urban planning, landscaping 
administrative department or the entrusted organization obtains the current status and data of the planning implementation through corresponding theoretical methods and technical means, based on the evaluation model and evaluation criteria. Implementation effect and planning implementation of the plan.

\section{Urban green space system planning and implementation evaluation system}

The connotation of the urban green space system planning implementation evaluation can be seen: the implementation evaluation on the one hand studies the coincidence degree between the planned and implemented green space status, and on the other hand studies the impact of the implementation of the plan on social, ecological and economic aspects. Therefore, the corresponding evaluation indicator system should include implementation consistency and implementation performance.

\subsection{Planning implementation consistency}

The implementation conformity evaluation is used to measure the degree of agreement between urban green space system planning and implementation status. Therefore, the implementation of the consistency evaluation indicators from the two aspects of urban green volume planning and green space planning to select indicators. According to China's urban green space system planning content and implementation mechanism, the impact factors are collected, and the consistency evaluation indicators are initially selected. Finally, the Delphi Method is used to confirm the evaluation indicators.

\subsubsection{Green quantity planning indicators}

The green quantity planning indicator is the main indicator to measure the overall greening level of Chinese cities. In the process of planning the urban green space system in China and the selection of "ecological garden city" and "garden city", the main indicators of the three green indicators are the green rate, green coverage and per capita park green area. The "Climate Standards for Urban Landscaping" (GB/T50563-2010) puts forward corresponding requirements for the three major construction indicators of urban green space and the construction indicators of various green spaces.

Greening rate indicator is an important indicator of urban green space system planning, and it is also an important basis for the evaluation of urban greening in various cities. Therefore, there are sufficient reasons for the evaluation of urban green space system planning and implementation to be included in the evaluation index system. Greening rate of the built-up area is based on the scope of urban construction land and covers the green area of other green areas, but other green areas cannot exceed $20 \%$ of the total green area of construction land.

Green coverage rate is a derivative indicator of the green rate, and green coverage rate index is generally greater than the green rate indicator. The green coverage rate has a great relationship with green space rate. Under normal circumstances, the two have a synchronous growth relationship. Green coverage rate can reflect the overall greening level of the city and effectively reduce the urban heat island effect. Therefore, the green coverage rate is also included in the evaluation index.

Park green space is the core component of the urban green space system. The land area in the green area system of the built-up area also occupies the largest proportion. It bears important functions such as daily leisure, fitness and recreation, and has disaster prevention and mitigation for the city. Significant potential value, so it is included in the urban green space system planning implementation evaluation system. At present, the urban population of the built-up area refers to the resident population of the built-up area (including the registered population and temporary resident 
population). The urban population data and urban built-up area planning are specifically responsible by the public security department and the planning department, which easily cause the built-up area and the statistical population. Inconsistent situation. Therefore, the population of special areas such as scientific research units and industrial and mining plants outside the built-up area are not included in the demographic scope of urban built-up areas.

\subsubsection{Spatial planning indicators}

Many cities in China due to the lack of expectations for social development or the lack of monitoring of the implementation of green space system planning, some of the planned areas are not implemented as planned or not implemented. The spatial deviation was originally proposed by Professor Alterman through the comparison of the range of cells drawn. It refers to the ratio of the current green space that has been implemented but not within the planning area to the planned green area. The larger the spatial deviation value indicates that the urban green space system planning implementation process does not meet the planning area, the more the planning and implementation are inconsistent.

$$
\mathrm{D}=(1-\mathrm{Ax} / \mathrm{Ag}) \times 100 \%
$$

Where Ax is the planned green area and Ag is the planned green area.

The urban green space system planning is evaluated by the spatial deviation index. The urban green space is divided into three parts according to the planning implementation part, the non-planning implementation part, and the planned unimplemented part. On the one hand, starting from the overall urban green space, the overall deviation of urban green space system planning is analyzed. On the other hand, the spatial deviation of various types of green spaces in the city is evaluated separately to analyze the characteristics of the consistency of planning and implementation of different green space types.

\subsection{Planning implementation performance}

The performance evaluation of urban green space system planning implementation is a measure of the value of urban green space. Correct understanding and grasping the value of the evaluation object is the premise for scientific evaluation and the basis of select the performance evaluation indicators. Before assessing the urban green space system, it is necessary to clarify the value of the urban green space.

In essence, urban green space is part of the government's public service products. The public property of urban green space should first be reflected in its social service value. The social service value of urban green space should include recreational entertainment function, cultural education function, use function, disaster avoidance and disaster relief function, spiritual function, etc. In addition, the planning and construction of urban green space system has a positive protective effect on the ecological environment. Due to the global temperature rise and the rapid development of the domestic tourism economy, urban green space also shows some direct or potential economic benefits.

Implementation evaluation performance evaluation draws on foreign greenway network planning evaluation, landscape performance evaluation, EU urban green space comprehensive evaluation, domestic scholars' evaluation of green space system status and related research on implementation assessment. Through the analysis of the literature frequency and the opinions of the consulting experts, the three levels of social services, economic value and ecological benefits are selected. It also includes 12 secondary evaluation indicators such as: park green space accessibility, green space disaster prevention and avoidance rate, public satisfaction, service facility perfection, air quality 
excellent rate, heat island effect index, acoustic environment quality index, surface water pollution index, seedling production value, carbon sequestration oxygen release value, tourism economic output value and land premium rate ,etc.

\subsection{Planning Implementation Evaluation Index System}

In summary, the criteria layer of the implementation evaluation index system of urban green space system includes implementation consistency evaluation and implementation performance evaluation two aspects. The implementation of consistency evaluation indicators selects green quantity planning indicators (green space rate, green coverage rate, per capita park green area), Spatial deviation degree of green space,3 primary evaluation indicators, 9 secondary evaluation indicators; The implementation of performance evaluation indicators selected three levels of social services, ecological environment, economic benefits, 12 indicators Secondary evaluation indicators (Table 1).

Tab.1 Index of quantitative evaluation

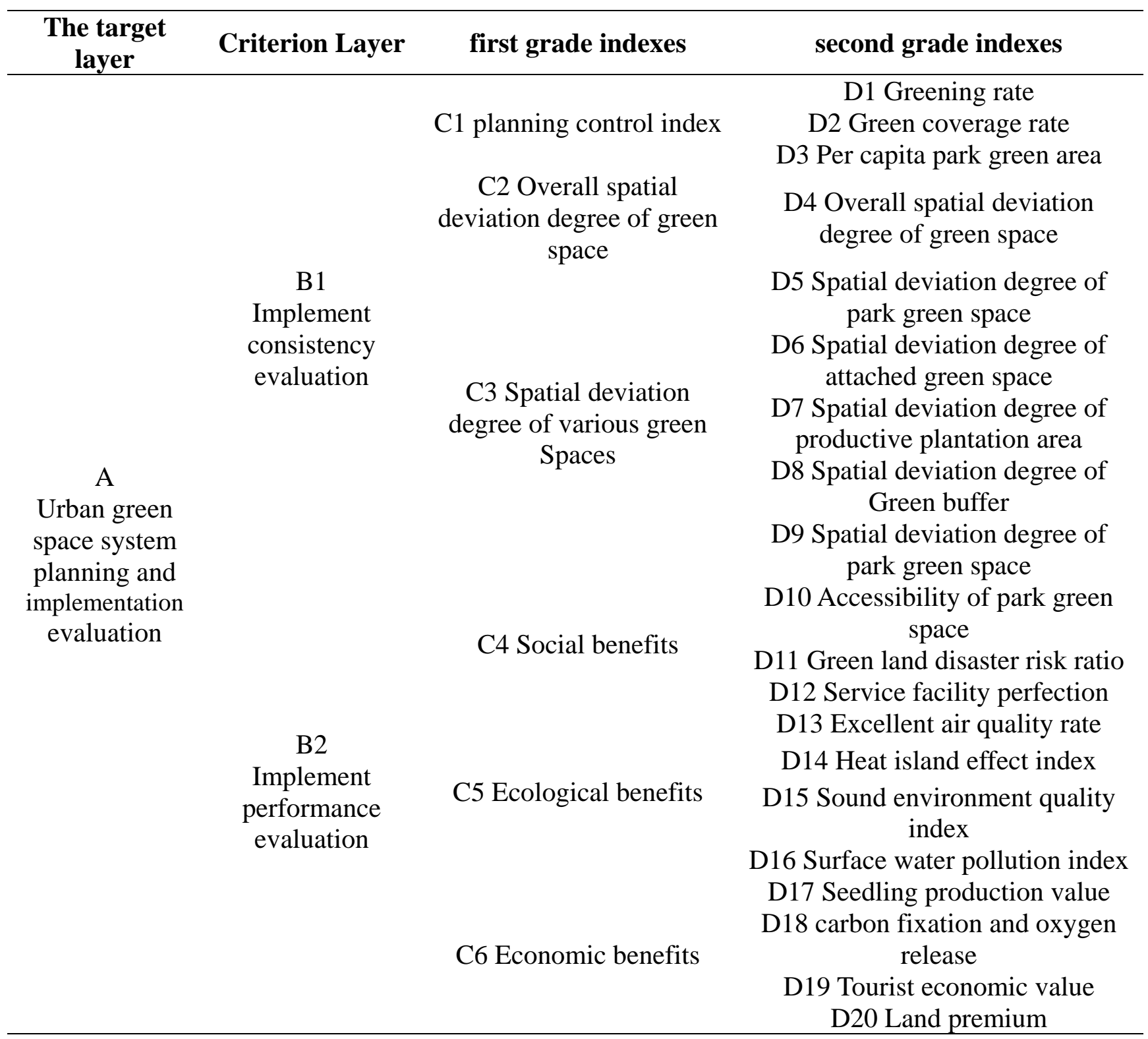




\section{Conclusion}

The urban green space system planning is a special plan of the urban master plan and the core carrier of the urban artificial ecological environment. China's sixth census shows that about one-third of the urban land used for urban construction covers 700 million people, and urban green space construction has become an important part of ecological civilization construction. Due to various social, political and economic factors, it is difficult to strictly implement urban green space system planning, and the legal effect documents for ensuring the implementation of urban green space system planning are also weak. Compared with land use planning and urban planning, the research on urban green space system evaluation in China is stagnant at the level of current status evaluation. The research work on urban green space system planning implementation evaluation needs to be improved. The research perspective, monitoring mechanism and feedback route are urgent government and scholars advance from the discipline and legislative level.

\section{References}

[1] Hong wuyang, Liu yongxue, Li manchun, Liu min, Tong lihua. Study on the method of land use overall planning implementation evaluation [J]. Land and resources science and technology management, 2013, 30(5):68-73.

[2] Red army, dany li. Analysis on technical methods of periodic assessment for the implementation of new general land use planning [J]. Land and resources information, 2013(8):38-41.

[3] He Jinghuan. Two perspectives of urban planning implementation assessment [J]. International urban planning, 2014(1): 80-86.

[4] Xi guangliang, Zhen feng. Discussion on ideas and methods of urban planning assessment based on big data [J]. Journal of urban planning, 2017(1):56-62.

[5] Zhang T. Innovation in Chinese Urban Governance: The Shanghai Experience [M]// Hambleton R, Gross J S, eds. Governing Cities in a Global Era: Urban Innovation, Competition, and Democratic Reform. New York: Palgrave Macmillan, 2007: 113-125.

[6] Lin liwei, Shen shan, Jiang guoxun. Research progress of urban planning implementation assessment in China [J]. Planner, 2010, 26(03):14-18.

[7] Zhang T. Innovation in Chinese Urban Governance: The Shanghai Experience [M]// Hambleton R, Gross J S, eds. Governing Cities in a Global Era: Urban Innovation, Competition, and Democratic Reform. New York: Palgrave Macmillan, 2007: 113-125.

[8] Tian L, Ma W. Government Intervention in City Development of China: A Tool of Land Supply [J]. Land Use Policy, 2009, 26(3): 599-609. 